\section{Spring 『rials}

\section{Maria Comninou}

University of Michigan

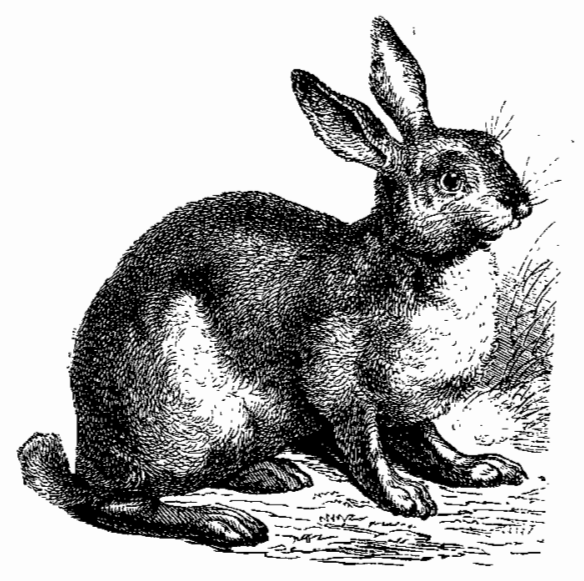

A mild winter was followed by an unseasonable cold spell, and spring was late in coming in this northern part of the midwest. Underneath a layer of mushy clay the ground was still frozen hard. Seeing it like this, it was difficult to imagine that any life could eventually spring out of it.

It was already April when crocuses started to come up reticently, only to be cropped back to the ground by rabbits having their early breakfast. Herds of deer, sometimes as many as seventeen, could be seen among the tall, still naked, oak trees, searching for the first new leaves. They refrained from eating the daffodils, but showed a hearty partiality for the bright red tulips. Effortlessly, they leaped over the fence, designed to keep our dogs in, and grazed a few yards from the house, right in front of the bay windows. Our smallest and noisiest dog gave the alarm with a deep growl, and a Pandemonium of barking, howling and crying followed from window to window to door.

The days lengthened and brightened, and our walks in the woods were transformed with the fragrance of new vegetation and the sights of tiny, pink and white, nameless wild flowers, almost as plentiful as the blades of grass. Occasionally a flash of white would inark the trajectory of a cottontail fleeing dogs and humans alike.

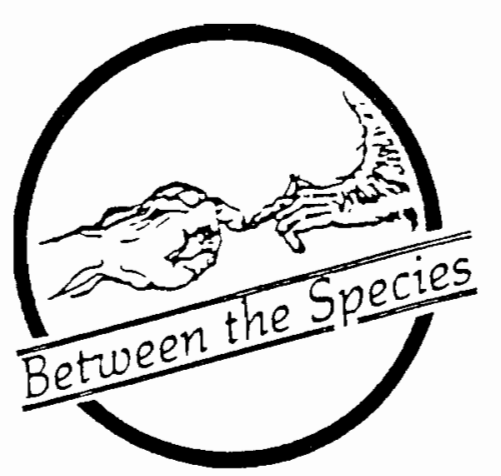

The exuberance of new life and beauty was somewhat tempered by the appearance of a myriad of sticky white tents, occupying the branching points of the wild cherry trees. Tiny caterpillars, growing a little every day, could be seen wiggling under the thick, semitransparent substance of the tent. This year, for humane and ecological reasons, I had persuaded my husband not to spray them. In the beginning, he was glad to be rid of a time-consuming and unpleasant job. However, as the caterpillars grew and started eating every single wild-cherry leaf, leaving behind a trail of their sticky shrouds, he started having second thoughts. "They are killing the trees," he said. "In my book cherry trees are higher up the ladder than tent caterpillars." Interminable arguments would follow, in which each side tried to weigh the effects of poisoning the environment or killing with ecological but equally inhumane means versus doing nothing. In the end my husband admitted that these trees would die anyway under the shadow of the oaks, and that his real reasons were purely aesthetic. The caterpillars were now fully grown and were clinging in grape-like fashion one on top of the other in a writhing, black mass. Although each one had a dark green hue and a delicate, hairy body, the overall effect was somewhat gross. There were so many, you could hear the continuous hum made by the sound of their droppings falling on last year's oak leaves.

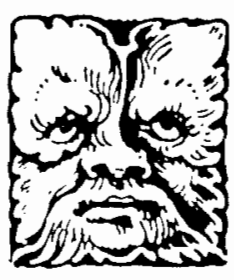


Caterpillars were not on my mind as I was preparing the injections for the sick cats in the so-called ICU room of the clinic that Sunday morning. I had arrived at the shelter at 7:00 a.m. before anyone else did, but after three hours of work I was still behind schedule. My job as a volunteer at the shelter was to take care of the clinic animals and give treatments to any stillconvalescing animals at the shelter. It was a job that should only take two hours in the morning and an hour in the afternoon. But I wasted time playing with the two resident cats, or trying to figure out what would entice the ICU cats to eat, or trying to pacify the puppy which was isolated in the vet's office for lack of space. Rena had come as a stray with a broken leg, but because she also had kennel cough, we could not keep her in the clinic area, and she was very unhappy by herself. She was a black, slick mutt with floppy ears still sticking to her head, dying for attention and company. It was impossible to keep her still: she was pawing, wiggling and wagging her entire behind while licking and chewing at any part of a living being's anatomy she could reach. In spite of her young age and all her excitement, she kept her cage clean: there were no accidents for me to clean over the fourteen-hour period she had remained in the cage overnight.

The shelter was a depressing place to be in spring. The kitten cages, empty in early January and February, were now overflowing, and more kittens were coming by the basketful. As space pressure built up, the shelter had to euthanize those that were not adopted within a week. With an abundance of kittens, the adult cats had a slim chance of finding homes. It didn't pay to get sick either. The ICU was full now. It was strange to try to cure sick cats on one hand, while killing healthy ones with the other. However, the philosophy was that every animal deserved a chance to be adopted. This meant getting well enough to be in a cage at the shelter for all visitors to see, at least for a week. Spring did not make much difference for the dogs; we had puppies all year round.

As I was ready to go to the ICU room again, Ingrid popped her golden head through the door: "Are you a wildlife rehabber?" she asked in her sweet, babyish tone that could fool those that did not know her. As assistant manager, she was very efficient, but too certain of her righteousness over life and death decisions for my liking. But of course I needed to blame somebody at hand for the spring slaughter; the faceless public was too remote.
I guessed now that her question was loaded, so I replied carefully, that, yes, I had taken the wildlife rehabilitation course but had no experience whatsoever. She had these three bunnies that needed rehabilitation, and all the wildlife volunteers had their hands full already, she replied. I countererl that I had a sick cat at home; she needed fluids, and I couldn't possibly take anything else on.

"Oh, but they only need feeding twice a day," she said, and seeing me hesitate continued, "come, I'll show you."

The first bunny, in a shoe box, had a terrified look in his eyes. The eyes were open, but the ears were still clinging to the back of his head. He would be ready for release soon, Ingrid explained. Lot, as I named him, was the only one of his litter that survived the attentions of a scavenging dog. The other two bunnies were in a small carton box wrapped in dirty towels. They were tiny, and looked more like aborted fetuses (no, I haven't seen any of those!) than rabbits. Ingrid was firing instructions for their care and feeding. "Write it down," I interjected.

It was noon when I arrived back home. It was wet and miserable outside, and I had kept the heat on high during the half-hour drive from the shelter. Most of the drive was along a semi-rural road littered on both sides with the dead bodies of squirrels, opossums and raccoons. Most of the accidents occurred at night, but I had to keep my eyes open, and I was not at all sure that I could react in time, in spite of what my bumper sticker said.

I left my pitiful charges in the car and rushed in the house. "Tom, put the dogs and cats in the greenhouse and keep them quiet. I have three baby rabbits with me." The "greenhouse" had become the ante-room from the back door to the house. In the three hours before I had to leave again for the shelter, I had to prepare the rabbits nests, buy some whipped cream to mix with their special formula and drive to the other side of the town to pick up antibiotic for Clot and Pot, who had dog scratches on their belly. "Don't feel bad, if they die," Ingrid had said. "Most rabbits don't do well in rehab, and these had a nasty shock."

There were plenty of materials in our property to make a natural environment with food for the rabbits: oak leaves, fresh grass, clover and Queen Anne's lace. There were a lot more wild plants, but I did not know whether rabbits could or should eat them.

Between caring for the rabbits, who were safely placed in the spare bedroom upstairs, I asked Tom's 
help with Theone, my ailing cat. After a month of strange and unresponsive symptoms, and in spite of attempts at treatment from three vets, she had stopped eating or drinking and kept vomiting. It was close to a week now, and I had to try to give her fluids under the skin. She hated the whole procedure, and fought like only a cat knows how. Tom, protected by his thick work gloves, tried to hold her still, and I tried to hold the needle and part of the cat in place. We only managed $50 \mathrm{cc}$ this time, before she leaped with a scream. She now sat on our bed licking the sore spot on her back and looking at me over her shoulder with accusing eyes. I was fast coming to the conclusion that what I did was worse than useless; it was making Theone too upset to be of any help. The pill that was supposed to quieten her stomach seemed to make her vomit more. As iny husband kept saying, I was doing to her all the things I would refuse to do to myself. I loved Theone, and I was afraid that I was going to lose her to FIP or some other AIDS-like disease, just like the cat I lost six months ago and the one before her. However, all the blood tests came back negative, and the vet called her the "mystery cat."

It was time to start planting my "veganic" garden, that is, my organic garden growing without the use of animal fertilizers. Tom had toiled on it the two previous weekends and he was anxious to see me planting something now. He thought that it could not wait any longer. So after the ordeal with Theone we drove to the garden center in separate cars. I chose tomatoes, peppers, cucumbers, herbs, etc. and left them with Tom, since I had to pick up the antibiotic on my way to the shelter. At Polly's apartment the sitter was holding the baby; one dog was in a cage; and the other one followed her young boy around. The cats were in hiding. There were three baby squirrels in a cage in the bathroom. It looked more chaotic than anything in my house; at least I had more space and no babies.

With this uplifting thought I arrived at the shelter to be greeted by an eager Ingrid: "I left you a message at the clinic door," she said, and I thought I had won a price for stupidity. "Two more rabbits came, the same size as the first one, and I would like you to take them. In any case, it is better that Lot has company." "O.K.," I murnured inaudibly.

It seemed all wrong. I cared for the animals, of course, but there was no shortage of rabbits or of cats, or of people for that matter. The rabbits were the victims of urbanization, but maybe the dogs could be seen as laking the place of their natural predators. As for the cats, I had an ongoing unresolved conflict. Every time I fed them, I could not forget the fact that I was helping slaughter a cow or a chicken, not to mention the tuna and dolphin connection. I had vowed not to adopt another cat until a vegan diet for cats was established. There was some recent work pointing in that direction. My dogs were already practically vegan, and much better for it. Here at the shelter it was too much to expect vegetarianism for dogs. My vegetarian dog food was at least twice as expensive as the regular brands and had to be ordered from the other end of the country. It seemed that you could not be compassionate unless you were rich or at least had enough leisure time to cook your own dog food.

Back at home, I put the two new rabbits, Dot and Spot, with Lot. I noticed that their eyes were not completely open, but they seemed to be only a little smaller than Lot. As it was evening, I tried to feed Clot and Pot. They screamed in terror when I touched them. Ingrid said that they could not hear anything yet, but the others could, and my little dog was whining outside the bathroom door. I asked Tom to get her outside. These tiny babies did not look as if they were going to make it. Nevertheless, I fed them a bit of the warmed formula with a small syringe and put them back in the warm nest I had made from soft cloth within their box. I assumed that the other three could eat on their own. In any case Dot and Spot resisted feeding strenuously.

By evening Pot was dead and Clot followed soon after. Lot seemed to be eating the natural food in the box, and there were tiny droppings around the two nests I had made in the bigger box. I was not sure about the other two, so I called an experienced rehabilitator. She said I should try feeding them formula until their eyes were fully opened. I tried two times, and I was successful next day, the second time.

By mid-week we were ready to release Lot. His ears were straight up, and he was munching in my presence, as long as I did not move. There was a three-acre, partlywooded and partly-open area outside our dog fence and next to our enclosed vegetable garden. No dogs were going there. However, it was still a bit chilly and wet, and we decided to wait another day.

Next day we released Lot. That afternoon, a big bird was circling the sky. We had hawks and owls in the woods. I did not begrudge them their meal, but not with my rabbits, please! I felt like a mother worrying about sending her young into the cruel world out there! But 
of course my rabbits were happy to be free, and there was plenty of fresh food for them, at least until winter.

In the meanwhile Dot and Spot had opened their eyes, but their ears were not quite up yet. I kept them two more days, growing anxious about their mental state, and then released them. For a week I kept looking for them, and although I saw a lot of bigger rabbits, my little ones had hidden themselves in the woods and would not come out by day. Gradually, I relaxed.

My cat had also healed herself, it appeared. After I reluctantly forced the last, I told myself, pill down her throat, she went to the greenhouse and found some fresh grass I had brought in earlier. She ate a few blades and proceeded to throw up the lot, including my pill. I said, "OK, Theone, I'll let you die in peace." No more pills, no more fluids. That night she came to my side on the bed and pawed me; this was a sign that she wanted food. I did not believe her, because for a week she was asking for food but she would not eat anything. Half asleep, I reached for the little tin by the bedside where I kept some dry cat food for her, because she refused to eat from the bowls messed up by my other big, slobbering cats. Slowly, she ate two pellets, spitting several bits in the process. Tom said that it was a last sparkle before the end. However, by the end of the week she looked as plump as a full grown May rabbit, and had returned to her old tricks.

"These damn caterpillars," exclaimed Tom. "They have found my climbing rose and have eaten all the buds! I'll kill them the next time."

They had grown fatter and hairier, and they were now everywhere. They could be seen climbing the wooden fence next to the house, in bunches on the trunk of the oak trees, on the picnic table, on my husband's clothes and on the dogs' fur. In what seemed a tireless striving upward, they would climb on anything that stood up from the ground: the car tires, the garage door, stones, blades of grass, tree stumps. Caterpillars became an obsession and an omnipresence. After a while, the mind would convert any moving dark line in the field of vision into a crawling caterpillar!

"Did you leave the gate to the garden plot open?" asked Tom the same evening. I vehemently denied doing it.

"You must have done it," he insisted, "and the rabbits knew it was you; they ate my lettuce and pole beans, but left your lettuce and peas alone!"

"They don't care for carnivores," I replied.

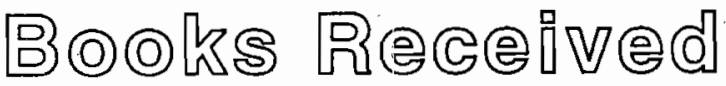

Lewis Gompertz

MORAL INQUIRIES

On the Situation of Man and of Brutes

Peter Singer, ed.

Fontwell, Sussex: Centaur Press Ltd. (The Kinship

Library), 1992

forward, preface, $160 \mathrm{p}$

$£ 8.99$ paper

distributed in U.S. by International Society for

Animal Rights, Inc., Clarks Summit, PA

\section{J. Howard Moore}

THE UNIVERSAL KINSHIP

Charles Magel, ed.

Fontwell, Sussex: Centaur Press Ltd. (The Kinship

Library), 1992

introduction, preface, $331 \mathrm{p}$, appendices, index f10.99 paper

distributed in U.S. by International Society for

Animal Rights, Inc., Clarks Summit, PA

\section{Bill Neidjie}

SPEAKING FOR THE EARTH

Nature's Law and the Aboriginal Way

Washington: Center for Respect of Life and

Environment, 1991

forward (Michael W. Fox), introduction, $58 \mathrm{p}$

$\$$ ? paper

\section{Richard D. Ryder}

PAINISM

Ethics, Animal Rights and Environmentalism

Cardiff: Centre for Applied Ethics, 1992

$15 \mathrm{p}$

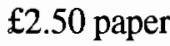

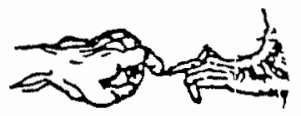

